\title{
O registro do indizível: um olhar sobre a arte fotográfica a partir dos pressupostos de Roland Barthes
}

Sandra Klafke

UNISINOS

Jorge Pedro Sousa

Universidade Fernando Pessoa - Portugal

\section{Resumo}

Este artigo aborda a fotografia do ponto de vista da arte e, para tanto, parte das categorias de studium e de punctum e toca a potência de "isso foi", elaboradas por Barthes (2009a). Esta escrita reflete acerca do lugar do contemplador da imagem e sobre a impossibilidade de que a fotografia se revele em todas as suas dimensões, ou seja, que o espectador a apreenda em totalidade. Nesse viés, explora-se a noção de que a imagem é um universo refrator de inúmeras semânticas e que o olhar do espectador só é capaz de alcançar, quando frente a ela, os traços imagéticos que reflitam a si mesmo.

Palavras-chave: fotografia; contemplação; experiência.

\begin{abstract}
This article approaches the photograph from the point of view of art and, therefore, starts from the categories of studium and punctum and reaches the potency of "that has been", developed by Barthes (2009a). This writing reflects about the place of the contemplator of the image and about the impossibility that the photograph reveals in all its dimensions, in other words, that the beholder apprehends it in its totality. In this perspective, the article explores the notion that the image is a refractor universe of many semantics and that the look of the spectator is only able to achieve, when in front of it, the imagetics traits that reflect himself.
\end{abstract}

Keywords: photography; contemplation; experience. 


\section{Introdução}

1. BARTHES, Roland. A câmara clara: nota sobre a fotografia, 2009a.

2. BARTHES, Roland. O óbvio e o obtuso, 2009b, p. 155. 3. BARTHES, Roland. Aula,
1978.

4. Ibidem, p. 16.

5. KLAFKE, Sandra R. Da (re) criação enunciativa da experiência bumana: a fotografia como testemunbo [Tese], 2016, p. 125.
A imagem fotográfica conta uma história, uma história congelada em superfície fotossensível. O rastro escrito com luz em imagem narra, delimita e orienta o processo de significação do objeto visual, ao mesmo tempo em que captura a atenção e o imaginário de quem o contempla. A significação que emerge da fotografia, seja ela em foto única ou em sequência narrativa, é explorada na teoria barthesiana, especialmente, pelas categorias de studium e de punctum $^{1}$, a partir das quais este artigo parte em busca de uma reflexão acerca da possibilidade de que a imagem refrate inúmeras semânticas, tomadas aqui como potências de "isso foi", ou seja, como potências que revelam que o referente esteve lá no passado, momento em que foi capturado e transformado em imagem. A motivação para a escrita da perspectiva em questão é a noção de "responsabilidade da obra", mencionada por Barthes - em $O$ óbvio e o obtuso, ao observar a pintura de André Masson -, quando descola a obra do criador e amplia seu escopo para além da "propriedade estreita" (criador), realocando-a para um "[...] espaço cultural que é aberto, sem limites, sem vedações, sem hierarquias [...]"2.

Faz-se importante destacar que, neste texto, a discussão sobre a arte fotográfica do ponto de vista daquilo que não se pode dizere, do que não cabe em palavra por estar alocado nas inúmeras possibilidades de refração de significados interpostos pelas relações estabelecidas pelos próprios elementos que constituem o microcosmo imagético, tem fundamento na aula inaugural de Barthes, proferida no ano de 1977, no Collège de France, quando, para falar da arte, tomando, por exemplo, a arte que se realiza pela palavra (Literatura), o autor manifesta o entendimento de que é nela que a língua, um dia por ele entendida como fascista, porque nos "obriga a dizer", pode ser ouvida fora do poder "no esplendor de uma revolução permanente da linguagem". É no esplendor de uma revolução permanente da linguagem que, aqui, busca-se a fotografia como arte em que o homem, diferentemente da arte literária, inscreve sua impressão sobre o mundo em um "[...] espaço para o exercício da linguagem sem voz e nem palavra", porém transbordado de significação.

Sendo assim, este texto, que explora o que da fotografia emana como indizível e como "isso foi", constrói sua reflexão em fundamentos barthesianos, mas, quando houver a necessidade de palavra para além dos ensinamentos do autor, busca argumentos em estudiosos das áreas da fotografia, da filosofia e da linguagem. Esse movimento só é possível porque entendemos que o pensamento de Barthes transcende à separação das disciplinas em compartimentos, rejeita os moldes impostos pelo fazer científico moderno e explode em um exercício teórico que 
funde experiência intelectual e experiência sensorial, tal como pode ser lido em A câmara clara. Para cumprir com o proposto, o item subsequente a esta introdução aborda as categorias de studium e de punctum na teoria de Barthes, estende o olhar para uma fotografia e explora a ideia da arte fotográfica como propagadora de significação e lugar de "isso-foi".

\section{Da denotação à significação: o encaixe para a contemplação}

“[...] porque era uma fotografia, eu não podia negar que tinha estado lá. [...] Nenhum escrito pode me dar essa certeza", eis a afirmação de Barthes, em A câmara clara, como frase inicial deste item simplesmente porque revela, de alguma forma, o prisma através do qual o autor compreende as imagens fotográficas. Se a fotografia dá a ver aquilo que não posso negar é porque dela advém o testemunho proveniente de um registro singular de determinados tempo e espaço. Esse testemunho se encontra na inegável presença do referente, cuja existência atesta que alguém o viu. O isso foi confirma que o elemento existiu e foi capturado pela objetiva, o noema $a^{7}$ é presentificado no processo de contemplação, ainda que, na imagem, seja a representação de algo que, hoje, já não é mais, de algo que "foi”".

O clique fotográfico é um instante, nunca mais poderá ser repetido, mesmo que em detalhes. O tempo do registro da imagem é sempre presente, singular e irrepetível. Já o tempo que emana da imagem fotográfica é outro, é “a quarta dimensão. Podemos fomentar associações mentais entre a ideia de tempo e a disposição espacial dos objectos em uma fotografia ${ }^{8 "}$. O tempo da fotografia é uma representação mecânica, ou seja, é a face de um efeito de realidade promovido pelas escolhas do fotógrafo, pelo processo artístico a que ele submete seu olhar em consonância com o olho da lente. Capturar uma imagem é um processo contingencial e o resultado do registro é a evidência da singularidade de quem deseja comunicar um ponto de vista sobre o mundo. "Do ato-processo do ajuste mecânico da câmera: ângulo, distância focal, fotometragem, mais luz, menos luz, foco; enfim, todo o arranjo que ajusta a lente para a captura da imagem pelo fotógrafo é uma tomada de posição [... $]^{9 ’ ”}$.

Por conjugar em si as relações espaço-temporais e prestar testemunho acerca de determinada realidade ${ }^{10}$, a fotografia, permeada pela subjetividade de quem opera a câmera, ainda que revele traços latentes do mundo tal como o conhecemos, traz algo de indizível, algo de fugaz que é captado pelo olho do contemplador, mas, ainda assim, em parte escapa à definição em
6. BARTHES, Roland. A câmara clara: nota sobre a fotografia, 2009a, p. 128.

7. Ibidem.

8. SOUSA, Jorge Pedro.

"Fotojornalismo". Sebenda, 1994, p. 100.

9. KLAFKE, Sandra R. Da (re) criação enunciativa da experiência humana: a fotografia como testemunho [Tese], 2016, p. 134.

10. Realidade, leia-se no sentido de mundo que pertence ao mesmo tempo em que é pertencido pelo homem. 
11. AGAMBEN, Giorgio. $A$ potência do pensamento, 2015, p. 84.

12. BARTHES, Roland. $A$ câmara clara: nota sobre a fotografia, 2009a, p. 52.

13. Intersubjetividade: sentido de que o homem só se constitui como sujeito porque está em relação com o outro, seja ele real, imaginário, animado ou inanimado.

14. BENVENISTE, Émile. Problemas de Lingüistica Geral I, 1995, p. 286.

15. Potência: "Ancorado em Aristóteles, Agamben (2015) destaca que a impotência, contraparte da potência, não carrega consigo a ausência, mas sim a potência de não, isto é: toda impotência traz consigo a potência de não passar ao ato". KLAFKE, Sandra R. $\mathrm{Da}$ (re)criação enunciativa da experiência humana: a fotografia como testemunho [Tese], 2016, p. 80.

16. AGAMBEN, Giorgio. $O$ homem sem conteúdo, 2013a, p. 151. palavras: aquilo que foge emerge em experiência sensorial; o imaginário e a historicidade humana que constituem o contemplador criam para além daquilo que a imagem dá a ver. "Através do desdobramento irônico que a imagem opera, o olho que olha torna-se o olho olhado, e a visão se transforma em um ver-se a ver, em uma representação no sentido filosófico, mas também no sentido teatral do termo" ${ }^{11}$.

Quando explora a imagem fotográfica, Barthes revela, com base em sua experiência como contemplador, o despertar de seu interesse pelas fotografias a partir de duas categorias: studium e punctum; por meio das quais passou a diferenciar seu afeto por algumas imagens em detrimento de outras. Sendo assim, para ele, a categoria de studium comporta o despertar do interesse do espectador pela imagem. É a primeira instância de captura do imaginário, pois convoca a historicidade do contemplador. O studium comporta um testemunho latente que está para o que a fotografia guarda como fato denotado. Já o punctum não é proveniente daquilo que a imagem denota, mas do que ela oculta. Ele é o traço da subjetividade do fotógrafo que chega à percepção do contemplador: "[...] o punctum é um 'pormenor', isto é, um objeto parcial. Assim, apresentar exemplos de punctum é, de certo modo, entregar-me" ${ }^{\prime 2}$. É entregar-se porque revelar o punctum é apresentar detalhes sobre si mesmo, sobre sua descoberta, sobre o traço que o constitui como sujeito na linguagem. Deixar que transpareça o traço intersubjetivo ${ }^{13}$ que nos une ao fotógrafo é expor a nós mesmos, é revelar nossa subjetividade porque evidencia a maneira como vivenciamos a experiência de sermos nós mesmos; a subjetividade, pois, tem a propriedade de, como unidade psíquica, transcender "[...] a totalidade das experiências vividas que reúne, assegurando a permanência da consciência" ${ }^{14}$.

Se a arte é a autogeração da vontade em potência ${ }^{15}$, e sua razão de ser pode estar depositada na impossibilidade de que nela o ser humano desfrute de sua potência, podemos, por analogia, uma vez que tratamos da fotografia como uma forma de arte neste artigo, dizer que as imagens conjugam, em si mesmas, no processo de contemplação, ser (contemplador) e tempo (do referente, da captura e da contemplação), sendo, desta maneira, “[...] a eterna autogeração da vontade em potência. Como tal, ela se destaca tanto da atividade do artista quanto da sensibilidade do espectador para se colocar como o traço fundamental do devir universal" 16 .

Para alcançar o punctum e sentir a surpresa originada pelo choque de ter o olhar desperto na e pela imagem, o contemplador necessita preencher com sua experiência singular no mundo a lacuna que o separa da fotografia. $\mathrm{O}$ ato de preencher, aqui, não está para a ideia de que somos capazes apenas de nos relacionarmos, de estabelecermos afeto - para usar o termo que 
motivou a elaboração das categorias barthesianas -, com as imagens que tocam de alguma forma nossa memória e evocam experiências por nós vivenciadas. É preciso considerar que a fotografia, independentemente de convocar ou não algo vivido pelo contemplador, o lança para aquilo que há de não vivido nele mesmo: "[...] a fotografia nunca é mais do que um canto alternado de 'Olhe', 'Veja'[...]"'17.

A cada proposição de si como sujeito no mundo, o homem experiencia-se, acessando a historicidade que o constitui como vivente. Os ecos que carrega formam, em concorrência entre si, suas impressões sobre o mundo, e a eles o homem tem o direito de contrapor-se ou filar-se, a fim de que possa emergir como pertencente a um construto social e cultural saturado de valores diz-se saturado porque a cultura, tal como a entendemos, trata-se de um "[...] conjunto muito complexo de representações, organizadas por um código de relações e de valores: tradições, religião, leis, política, ética, artes, tudo isso de que o homem, onde quer que nasça, será impregnado no mais profundo da sua consciência $[\ldots]]^{\prime 18}$.

Voltando-nos para a ideia do homem diante da arte fotográfica, observamos que, para que a imagem fale algo para além do fato denotado é necessário que o contemplador consiga ordenar os elementos da cultura nela impressos e dotar de sentido o arranjo por eles formado. A fotografia apresenta-se como um sistema, como um todo do qual emana significação, por isso a evidencia de sentido se deposita no conjunto formador da obra. Com isso queremos dizer que é a partir do entendimento/do depósito do olhar sobre o todo que se pode, em detalhes, observar a significação dos elementos em estado isolado. Todavia, não podemos esquecer que:

[...] a arte fotográfica não coloca o homem em relação a outra coisa senão a si mesmo. A possibilidade desta afirmação se sustenta sobre o caráter testemunhal da fotografia enquanto espaço que estimula uma tomada de posição do contemplador que já foi por ela captado quando permitiu-se enredar pelo microcosmo imagético, ao ir além do fato denotado. ${ }^{19}$

Porém, do instante de contemplação algo sempre resta. O resto reside na impossibilidade de que o observador da imagem a alcance em todas as suas dimensões, interpretando-a por completo. Algo de indizível sempre resta no processo de interpretação da imagem, algo sempre escapa à percepção do contemplador, e é justamente aqui que reside a capacidade da imagem fotográfica de tornar visíveis dimensões da realidade desconhecidas ou, até mesmo, invisíveis ao olhar habitual: a contemplação é o ato a partir do qual é sempre possível vislumbrar um novo começo, notadamente marcado pela impossibilidade de que vejamos a imagem sempre da mesma maneira.
17. Ibidem, p. 13.

18. BENVENISTE, Émile. Problemas de Lingüistica Geral I, 1995, p. 32.

19. KLAFKE, Sandra R. Da (re) criação enunciativa da experiência bumana: a fotografia como testemunho [Tese], 2016, p. 138. 
20. Idem, p. 56.

21. KOSSOY, Boris. Fotografia e história, 2012, p. 130.

22. SOUSA, Jorge Pedro. "Fotojornalismo", 1994.

\section{AGUSTINI, Carmen.}

"Sujeito e singularidade: (n)a enunciação fotográfica", 2007 , p. 247-248.

24. KLAFKE, Sandra R. Da (re) criação enunciativa da experiência humana: a fotografia como testemunho [Tese], 2016, p. 137.
O resto diz respeito ao que é inarticulável pela palavra [...] A ideia de 'resto' está associada à impossibilidade de captar a realidade em sua positividade (tal como ela é); a realidade justamente evapora porque é indizível. A arte, porque promove uma renovação na linguagem legislada (a linguagem dita ordinária e, no caso da fotografia, a imagem que se preocupa com a fidelidade, com o retratar de forma direta a realidade), é que pode trazer algo desse 'resto' que 'permite' o testemunho. 'Resto' é o indício de que algo escapou ao controle do eu. A arte é o lugar em que o que escapa tem lugar. ${ }^{20}$

Aquilo que escapa é da ordem do punctum, pois, se o studium é a evidência testemunhal não velada, ou seja, a motivação latente por meio da qual o olhar identifica uma época, um estilo; uma situação cotidiana; um objeto; um alimento; enfim, um recorte visual de coisas que o observador reconhece como fragmentos de realidade, é no punctum que transcendemos o fato denotado, já que:

O significado mais profundo da imagem não se encontra necessariamente explícito. O significado é imaterial; jamais foi ou virá a ser um assunto visivel passível de ser retratado fotograficamente. $\mathrm{O}$ vestígio da vida cristalizado na imagem fotográfica passa a ter sentido no momento em que se tenha conhecimento e se compreendam os elos da cadeia de fatos ausentes da imagem. Além da verdade iconográfica. ${ }^{21}$

Sendo assim, a fotografia não é um mero registro biplanar de determinado(s) elemento(s) do mundo; a captura do olhar pode ser cativada pelos estímulos: repetição, contraste cromático e contraste luz-sombra, por exemplo ${ }^{22}$, e ela é capaz de conduzir o contemplador a vivenciar "aquilo que é referencializado e (re)enunciado por seus mecanismos: o olhar do fotógrafo, o recorte proposto, a lente, a objetiva, a luz, o foco, os mecanismos constitutivos da linguagem fotográfica e de seus dispositivos plásticos, fundamentais à singularização da fotografia"23. Nesse sentido, a fotografia sempre se situa no limite de uma constatação, de uma evocação que a presentifica a cada instante. É um "presente-passado-presente" ${ }^{24}$ renovado a cada contemplação. O referente, cuja latência grita aos olhos do contemplador, não é potente porque permite que se reviva o passado através da imagem, mas sim porque a imagem assegura sua existência de "isso foi".

A fotografia, tal como as demais artes, emerge na cultura porque é "feita" pelos homens, de um homem para outro homem (real ou imaginário; previamente definido ou não; pode coincidir ou não com o artista). O que os homens "leem" e "veem" nas imagens não é proveniente apenas do contato com a fotografia, mas mobilizado também pela memória, pois a “[...] 
arte gera uma espécie de transe [...] preparando tanto o autor quanto o ouvinte para uma experiência terrível ou sublime, sempre prestes a acontecer, ou que já aconteceu"25.

Vejamos a imagem abaixo, extraída da narrativa fotográfica Arquipélago ${ }^{26}$, de Cristiano Sant'Anna. Nela observamos um homem à janela. Há protótipos para o objeto janela e para o ser humano masculino socialmente partilhados, o que nos permitem uma rápida e fácil identificação desses elementos; isso é, portanto, o denotado pela imagem.

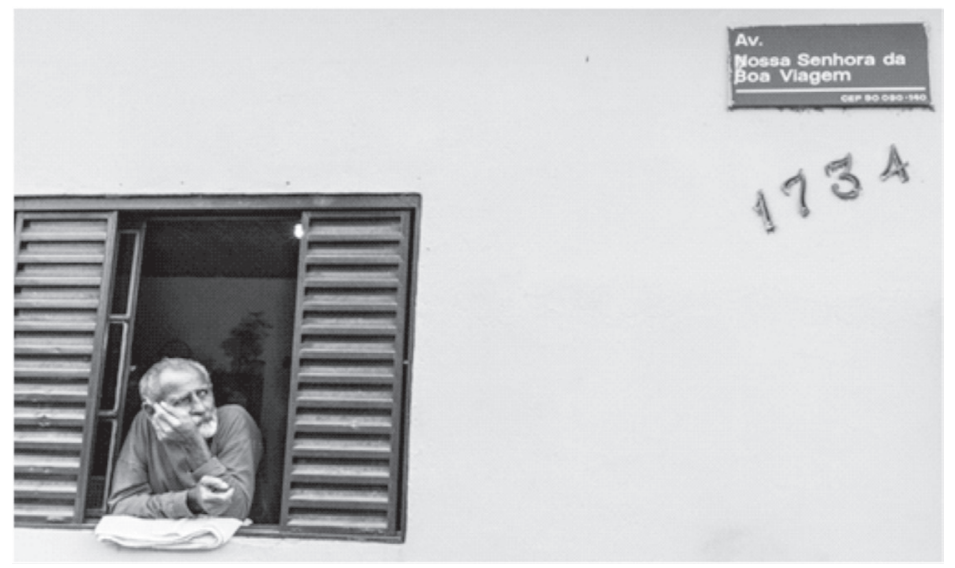

Fig. 1. Sant'Anna, 2014, p. 44.

$\mathrm{O}$ registro nos mostra que o referente foi, em determinado espaço-tempo, capturado pela objetiva: ele existiu. A fotografia prova essa existência através da própria ausência do referente, pois, uma vez congelado na bidimensão, ele já não é mais parte do mundo, mas parte do sistema formado pela imagem. O "isso foi" mostra que o fato denotado pela fotografia toca o real, um real onde, efetivamente, existiu um homem a observar a vida que passa diante de sua janela; ele é a evidência de um real passado cujo traço irrepetível reside no instante do clique: o fotógrafo viu o referente e pelo olho da lente o recortou no espaço-tempo. Hoje, o que a fotografia nos apresenta é um objeto parte de um sistema imagético do qual emana significação. A imagem transforma o referente em objeto bidimensional. "Toda fotografia representa em seu conteúdo uma interrupção no tempo e, portanto, da vida. O fragmento selecionado do real, a partir do instante em que foi registrado, permanecerá para sempre interrompido e isolado na bidimensão da superfície sensível" ${ }^{27}$.

Sendo assim, contemplar uma fotografia não é permanecer no nível da denotação, mas permitir que a interpretância fuja para uma dimensão em que fragmentos de memória adquiridos nas diferentes experiências que vivenciamos ao longo da vida tencionem a rigidez do traço latente na imagem e explodam em “[...] incapacidade de recepção de um evento que vai além dos
25. HARTMAN, Geoffrey H. "Catástrofe e representação", São Paulo, p. 224.

26. Arquipélago, de autoria do fotógrafo gaúcho Cristiano Sant'Anna, lançada no segundo semestre de 2014, é resultado de um trabalho de dezoito meses no conjunto de ilhas que forma o bairro de Porto Alegre/ RS que inspirou o título da obra. Constituída por sessenta imagens em preto e branco, sua elaboração foi motivada pelo interesse do fotógrafo em retratar a história da comunidade que vive nas ilhas, do ponto de vista econômico e social.

27. KOSSOY, Boris. Fotografia e bistória, 2012, p. 46. 
28. SELIGMANN-SILVA, Márcio. "A história como trauma", 2000, p. 84.

29. BARTHES, Roland. Aula, 1978, p. 19.

\section{TEIXEIRA, Marlene}

Terezinha Lopes. "Transgressão dos sujeitos em canções de Chico Buarque”, 2006, p. 121.

31. FREUND, Gisèle. Fotografia e sociedade, 2010, p. 188.

32. KLAFKE, Sandra R. Da (re) criação enunciativa da experiência bumana: a fotografia como testemunho [Tese], 2016, p. 145.

33. AGAMBEN, Giorgio. Ideia da prosa, 2012a, p. 112. 'limites' da nossa percepção e torna-se, para nós, algo sem forma"28. É a experiência subjetiva de ser a si mesmo carregada por cada ser humano que faz nascer, para cada um a seu modo, o punctum, a matéria significante da qual transborda o afeto pela imagem e, intersubjetivamente, nos liga ao fotógrafo porque nos estimula a nos comprometermos eticamente com os fatos por ele capturados, que, na essência da imagem, recolhemos como potências de "isso foi".

\section{Considerações finais}

No dizer de Barthes ${ }^{29}$, a arte "encena a linguagem, em vez de simplesmente utilizá-la [...]", num discurso "que não é mais epistemológico, mas dramático". Essa posição sobre a arte ecoa nas palavras de Teixeira ${ }^{30}$, para quem "é na arte que os acidentes ilegítimos e perturbadores da racionalidade científica encontram uma forma de representação, porque na arte, como no inconsciente, há um saber fundamental e primitivo que falta à ciência".

Pensando na fotografia como uma possibilidade de dar lugar ao que não tem lugar, como o abrigo daquilo que tenciona a racionalidade científica é que nos dirigimos para as palavras finais deste texto. Dessa maneira, no que tange ao instante de captura pela objetiva fotográfica, destacamos que o congelamento de um fragmento de "realidade" faz emergir não um simples objeto plasmado na bidimensão, mas sim um conjunto concatenado e revelador da experiência humana, pois "o valor, na fotografia, não pode apenas ser medido a partir de um ponto de vista estético, mas pela intensidade humana e social da sua representação óptica" 31 . Com relação à significação, observamos que ela "não depende unicamente do fato denotado, mas sobretudo da possibilidade de que o efeito dos elementos dispostos na imagem toque o homem a ponto de deslocá-lo daquilo que é literal para dentro de si mesmo[...]"32. A leitura, ou interpretação da imagem, portanto, vem de dentro, vem do corpo de quem a contempla. Nesse processo, a arte fotográfica se constitui como um dos lugares privilegiados para que se assista o nascer da criação de um testemunho acerca da condição humana.

Porém, a fotografia, em si mesma, quando interrogada pelo homem, cala. Somente ao homem é dada a oportunidade de colocar-se diante das coisas mudas. Diferentemente dos animais, ele tem o privilégio de irromper na palavra e ocupar o lugar de dizer, posicionando-se frente a um dito e, dessa maneira, também responder ao que há de "mudo" naquilo que diz. "A rosa informulada, a ideia da rosa, só existe para o homem" 33 . Portanto, a subjetividade que advém no processo de contemplação 
nasce do silêncio. A relação entre o contemplador e a imagem fotográfica é intersubjetiva e muda, por isso Barthes nos ensina que, para vermos bem a uma imagem fotográfica, necessitamos fechar os olhos e tirá-la “[...] do seu 'bla-bla-bla' vulgar: 'Técnica', 'Realidade', 'Reportagem', 'Arte', etc.: nada dizer, fechar os olhos, deixar que o pormenor suba sozinho à consciência afectiva" 34 .

\section{Referências}

AGAMBEN, Giorgio. A potência do pensamento. Ensaios e conferências. Tradução de Antônio Guerreiro. Belo Horizonte: Autêntica Editora, 2015.

- Ideia da prosa. Tradução de João Barrento. Belo

Horizonte: Autêntica Editora, 2012a.

- O homem sem conteúdo. Tradução de Cláudio Oliveira, 2.

ed. Belo Horizonte: Autêntica Editora, 2013a.

AGUSTINI, Carmen. "Sujeito e singularidade: (n)a enunciação fotográfica". Revista do Programa de Pós-Graduação em Letras da Universidade de Passo Fundo. vol. 3, n. 2, p. 245-254, jul./dez. 2007.

BARTHES, Roland. A câmara clara: nota sobre a fotografia. Lisboa: Edições 70, 2009a. . Aula. São Paulo: Cultrix, 1978. . O óbvio e o obtuso. Lisboa: Edições 70, 2009b.

BENVENISTE, Émile. Problemas de Lingüística Geral I.

Campinas: Pontes, 1995.

FREUND, Gisèle. Fotografia e sociedade. 3. ed. Lisboa: Vega, 2010.

HARTMAN, Geoffrey H. "Holocausto, testemunho, arte e trauma”. In: NESTROVSKY, Arthur; SELIGMANN-SILVA, Márcio (Orgs.). Catástrofe e representação. São Paulo: Escuta, 2000. p. 207-235.

KLAFKE, Sandra R. Da (re)criação enunciativa da experiência humana: a fotografia como testemunho. [Tese]. Universidade do Vale do Rio dos Sinos, Programa de Pós-Graduação em Linguística Aplicada, São Leopoldo, RS, 2016.

KOSSOY, Boris. Fotografia e história. São Paulo: Ática, 2012.
34. BARTHES, Roland. $A$ câmara clara: nota sobre a fotografia, 2009a, p. 64. 
SANT'ANNA, Cristiano. Arquipélago. Fotolivro. Porto Alegre: Editora Publicato. 2014.

SELIGMANN-SILVA, Márcio. "A história como trauma". In: NESTROVSKY, Arthur; SELIGMANN-SILVA, Márcio (Orgs.). Catástrofe e representação. São Paulo: Escuta, 2000. p. 73-98.

SOUSA, Jorge Pedro. "Fotojornalismo". Sebenda. Porto: Universidade Fernando Pessoa, 1994.

TEIXEIRA, Marlene Terezinha Lopes. “Transgressão dos sujeitos em canções de Chico Buarque”. In: DE CARLI, A. M. S.; RAMOS, F. B. (Orgs.). Palavra-Prima - as faces de Chico Buarque. Caxias do Sul: EDUCS, 2006, v. 1, p. 114-127. 